\title{
Perkütan nefrolitotomi pozisyonu tercihinde dikkat edilmesi gereken özel bir durum: megakolon
}

\section{A special condition for the position of pnl: megacolon}

Cihan Toktaş, Ali Ersin Zümrütbaş, Yusuf Özlülerden, Aykut Başer, Ömer Levent Tuncay

\section{Özet}

Perkütan böbrek taşı cerrahisi birçok avantajı olmasın rağmen komplikasyonsuz bir cerrahi değildir. Bu komplikasyonlardan bir tanesi de kolon yaralanmasıdır. Bu vaka sunumunda mobil böbrek nedeniyle pron pozisyonda perkütan nefrolitotomi yapılamayan 56 yaşında bir erkek hasta sunuldu. Bu tür hastalarda operasyon öncesi supin pozisyonda tomografi çekilmesi gerekebilmektedir. Bu vakada olduğu gibi mobil böbrek durumlarında tomografi eşliğinde akses oluşturulması veya supin PCNL seçeneği de göz önünde bulundurulmalıdır.

Anahtar kelimeler: Perkutan nefrolitotomi, pozisyon, megakolon.

Toktaş C, Zümrütbaş AE, Özlülerden Y, Başer A, Tuncay ÖL. Perkütan nefrolitotomi pozisyonu tercihinde dikkat edilmesi gereken özel bir durum: megakolon. Pam Tıp Derg 2020;13:445-448.

\begin{abstract}
Percutaneous stone surgery has lots of advantages but it is not a complication free surgery, one of these is colonic injury. In this report we presented a-56 year old male patient with mobile kidney. Because of mobile kidney we could not perform prone percutaneous nephrolithotomy. Supine tomography may be necessary for such patients. Also tract creation may be performed by tomography and supine percutaneous nephrolithotomy should be considered.
\end{abstract}

Key words: Percutan nephrolithotomy, megacolon, position.

Toktaş C, Zümrütbaş AE, Özlülerden Y, Başer A, Tuncay ÖL. A specıal condıtıon for the posıtıon of pnl: megacolon. Pam Med J 2020;13:445-448.

\section{Giriş}

Üriner sistem taşları bilinen en eski hastalıklardan birisidir ve Türkiye'de endemik olarak kabul edilmektedir. 20. yüzyılın sonlarına doğru anestezi ve teknolojideki ilerlemelere bağlı olarak taş hastalığının cerrahi tedavisi önemli ölçüde değişiklik göstermiştir. Bu değişikliklerden en önemlisi ilk kez Fernström ve Johannson tarafından 1976 yılında tanımlanan perkütan nefrolitotomidir (PCNL) [1]. Bu yöntem önceleri sadece seçilmiş hastalarda uygulanmakta iken giderek popülaritesini arttırmış ve günümüzde açık taş cerrahisi oranlarını \%4'ün altına indirmiştir. Perkütan taş cerrahisini en önemli avantajları hastaların normal yaşamlarına daha kısa sürede dönmeleri ve hastanede kalış sürelerinin daha kısa olmasıdır [2].

Perkutan böbrek taşı cerrahisi birçok avantajı olmasın rağmen komplikasyonsuz bir cerrahi değildir. Bu komplikasyonlardan bir tanesi de kolon yaralanmasıdır. Bu yaralanmaya neden olan en önemli durum retrorenal kolondur. Retrorenal kolon oranı alt pol düzeyinde sağ kolon için $\% 9$, sol kolon için ise $\% 16$ oranındadır [3].

Cihan Toktaş, Dr. Öğr. Üye. Kütahya SBÜ Tıp Fak. Hastanesi Üroloji Anabilim Dalı, Kütahya, Türkiye, e-posta: drctoktas@hotmail.com (orcid.org/00000002-6034-7896) (Sorumlu Yazar)

Ali Ersin Zümrütbaş, Doç. Dr. Pamukkale Üniversitesi Tıp Fakültesi Hastanesi Üroloji Anabilim Dalı, Denizli, Türkiye, e-posta: alizumrut@yahoo.com (orcid.org/0000-0002-1795-9678)

Yusuf Özlülerden, Dr. Öğr. Üye. Pamukkale Üniversitesi Tıp Fakültesi Hastanesi Üroloji Anabilim Dalı, Denizli, Türkiye, e-posta: yusufozlu35@hotmail. com (orcid.org/0000-0002-6467-0930)

Aykut Başer, Dr. Öğr. Üye. Hitit Üniversitesi Tıp Fakültesi Hastanesi Üroloji Anabilim Dalı, Çorum, Türkiye, e-posta: aykutbaser@mynet.com (orcid. org/0000-0003-0457-512X)

Ömer Levent Tuncay, Prof. Dr. Pamukkale Üniversitesi Tıp Fakültesi Hastanesi Üroloji Anabilim Dalı, Denizli, Türkiye, e-posta: oltuncay@pau.edu.tr (orcid.org/0000-0003- 4631-6337) 


\section{Olgu sunumu}

56 yaşında erkek hasta sol yan ağrısı şikâyetiyle polikliniğimize başvurdu. Hastanın çekilen direk grafisinde sol böbrek lojuna uyan bölgede yaklaşık 2,5 cm'lik opasite saptandı. Yapılan ultrason ve kontrastsız bilgisayarlı tomografi (BT) tetkikinde sol renal pelviste 25x15 mm'lik taş ve hidronefroz saptanması üzerine hastaya sol PCNL planlandı. Hastanın ülseratif kolit dışında başka ek hastalığı yoktu. Anestezi muayenesi öncesi yapılan tetkiklerinde anormal bulgu saptanmadı. İdrarkültüründe üremeolmadı Hastaya genel anestezi altında öncelikle üreter kateteri takılarak foley katetere tespit edildi. Ardından hasta pron pozisyona alındı. Pron pozisyonda ultrasonografi (USG) ile böbreğin lokalize edilememesi üzerine hastaya retrograd double-J (DJ) kateter yerleştirilerek işleme son verildi ve taşa 2 seans ESWL uygulandı. ESWL sonrası sol üreterde $5 \mathrm{~cm}$.'lik taş yolu izlenmesi üzerine hastaya sol üreterorenoskopi (URS), pnömotik litotripsi $(P L)$ ve DJ kateter değişimi uygulandı. Kontrolde sol böbrekte 4-5 adet 3-4 mm'lik taş saptanması ve üreter trasesinde taş izlenmemesi üzerine DJ kateteri çekildi. Hasta, 4 ay sonra sol yan ağrısı ve yüksek ateş şikâyeti ile başvurdu. Direkt grafide sol üreter alt uca uyan bölgede en büyüğü $6 \mathrm{~mm}$ olan 3 adet opasite ve USG'de orta derece dilatasyon saptandı ve flank pozisyonda perkütan nefrostomi takıldı. Hasta yatağına alındığında nefrostomisinin üriner sistem dışına çıktığı saptanması üzerine yapılan ultrasonda supin ve flank pozisyonda böbreğin normal yerinde izlenmesi fakat pron pozisyonda izlenememesi mobil böbrek olduğunu düşündürmekteydi. Sol böbrek pozisyonun belirlenmesi için hem supin hem de pron pozisyonda kontrastsız BT çekildi. Supin BT'de sol böbrek parankim cilt mesafesi $35 \mathrm{~mm}$ iken (Şekil 1) pron BT'de boyutları $85 \times 160$ mm'ye ulaşan ve ülseratif kolite bağlı olduğu düşünülen dilate kolon segmentinin cilt ile böbrek arasına girerek böbreği inferomediale ittiği ve cilt-böbrek mesafesinin 95 mm'ye ulaştı̆ı̆ı izlendi (Şekil 2). Bu nedenle hastaya BT eşliğinde prone pozisyonda $8 \mathrm{~F}$ kilitli nefrostomi kateteri takıldı (Şekil 3). Uygun antibiyotik tedavisi sonrası genel durumu düzelen hastaya yaklaşık 1 ay sonra sol URS, PL ve DJ takımı uygulandı. Takiplerinde ek sorunu olmayan ve taşsız hale gelen hastanın DJ stenti çekildi. Stent çekimi sonrası yapılan kontrollerinde de hastanın taşsız olduğu görüldü.

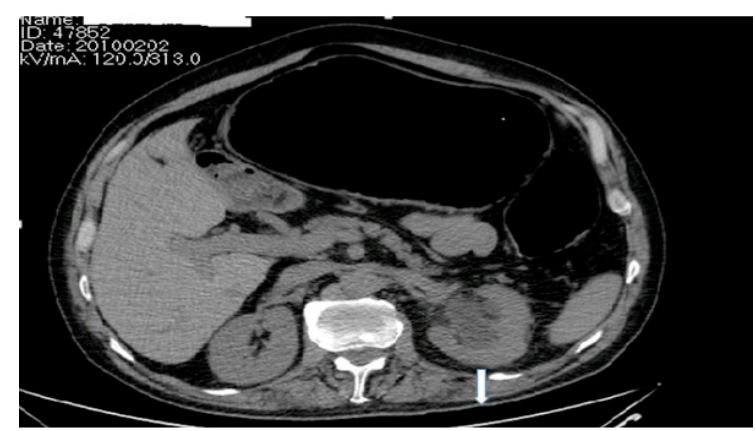

Şekil 1. Supin pozisyonda tomografi.

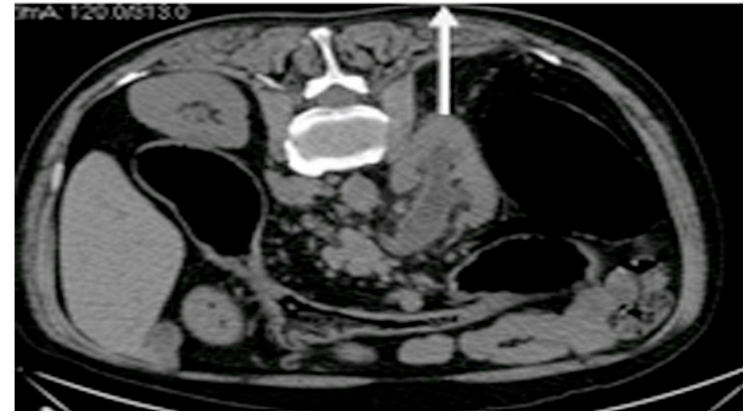

Şekil 2. Pron pozisyonda tomografi.

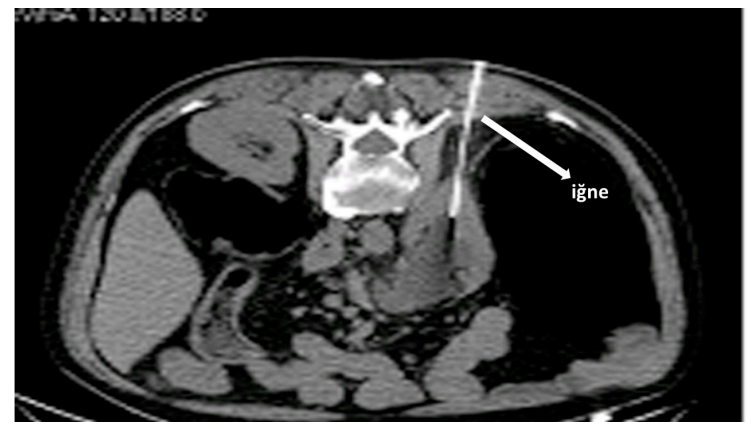

Şekil 3. Tomografi eşliğinde perkutan girişim.

\section{Tartışma}

Perkütan nefrolitotomi birçok avantaja sahip olmasına rağmen diğer birçok cerrahi gibi komplikasyonlara açık bir cerrahidir ve komplikasyonların sınıflandırılmasında modifiye Clavien sistemi kullanıır (Tablo 1).

2011 yılında yayınlanan ve 2001-2011 yılları arasında yapılan, 50 ve üzeri hasta sayısına sahip çalışmaları içeren ve bir derlemede Clavien 0 ve 1 grubundaki hastaların $\% 88,1$ oranında olduğu saptanmıştır. Hastaların kan transfüzyonu ve parenteral tedavi gereksinimi $\% 7$, cerrahi girişim gereksinimi ise $\% 4$ olarak saptanmıştır. Hayatı tehdit eden komplikasyon oranı $\% 0,6$ ve mortalite oranı ise $\% 0,04$ olarak tespit edilmişti [4]. Perkutan nefrolitotomi sonrası Clavien derece 4a komplikasyon olarak 
kabul edilen tekli organ yaralanmalarından bir tanesi olan kolon yaralanması farklı serilerde $\% 0,2-0,8$ oranında bildirilmektedir [5].

Kolon perforasyonu için en önemli risk faktörü retrorenal kolondur. Diğer risk faktörleri ise düşük vücut ağırlığı, kadın cinsiyet, abdominal operasyon öyküsü, sol PCNL, kronik kabızlık, atnalı böbrek ve mobil böbrek sayılabilir [6, 7].

Tüm bu risk faktörleri incelendiğinde operasyon öncesi dönemde en dikkatli olunması gereken ve belki de dikkatli anamnez ve görüntüleme ile elimine edilebilecek tek risk faktörünün mobil böbrek varlığı olduğu görülmektedir. Bu yüzden hastalarda mobil böbrek varlığı ve/veya bu duruma neden olabilecek bir hastalığın varlığı konusunda dikkatli davranılmalıdır.

Majör komplikasyon olarak sınıflandırılan kolon yaralanmalarından kaçınmak için PCNL öncesi özellikle görüntüleme açısından hasta hazırlığı çok büyük önem taşımaktadır. Cerrahi öncesi dönemde renal komşulukların tam olarak belirlenmesi özellikle de retrorenal kolon varlığının belirlenmesi için bilgisayarlı tomografi görüntülemesi rutin olarak uygulanmalıdır [3].

Sonuç olarak bu vakada olduğu gibi hastalara görüntüleme yapılan posizyonla cerrahi esnasında kullanılacak olan yöntemin aynı olması yani pron PCNL planlanan hastaların görüntülemelerinin de pron pozisyonda yapılması gerekebilmektedir. Bu vakada olduğu gibi mobil böbrek durumlarında tomografi eşliğinde akses oluşturulması veya supin PCNL seçeneği de göz önünde bulundurulmalıdır.

Supin PCNL yapılan 358 hastanın değerlendirildiği 2019 yılında yapılan bir çalışmada hiçbir hastada çevre organ yaralanması görülmemiştir [8]. Supin ve pron PCNL yapılan hastaların karşılaştırıldığı başka bir çalışmada ise supin yapılan cerrahilerde operasyon ve skopi sürelerinin daha kısa olduğu tespit edilmiştir [9]. Literatürde supin PCNL operasyonunun üstünlüğünü belirten bu şekilde çalışmaların yanı sıra iki yöntemin birbirine net olarak üstünlüğü olmadığını iddia eden çalışmalarda mevcuttur [10].

Çıkar ilişkisi: Yazarlar çıkar ilişkisi olmadığını beyan eder.

\section{Kaynaklar}

1. Tefekli A, Cezayirli F. The history of urinary stones: in parallel with civilization. Scientific World J 2013;423964. https://doi.org/10.1155/2013/423964

2. Matlaga BR, Assimos DG. Changing indications of open stone surgery. Urology 2002;59:490-493. https:// doi.org/10.1016/s0090-4295(01)01670-3

3. Boon JM, Shinners B, Meiring JH. Variations of the position of the colon as applied to percutaneous nephrostomy. Surg Radiol Anat 2001;23:421-425. https://doi.org/10.1007/s00276-001-0421-3

4. Seitz C, Desai M, Hacker A, et al. Incidence, prevention, and management of complications following percutaneous nephrolitholapaxy. Eur Urol 2012;61:146158. https://doi.org/10.1016/j.eururo.2011.09.016

5. Michel MS, Trojan L, Rasswiler JJ. Complicaitons in percutaneous nephrolithotomy. Eur Urol 2007;51:899906. https://doi.org/10.1016/j.eururo.2006.10.020

6. Juan YS, Huang $\mathrm{CH}$, Chuang $\mathrm{SM}$, et al. Colon perforation: a rare complicaiton during percutaneous nephrolithotomy. Kaohsiung J Med Sci 2006;22:99101. https://doi.org/10.1016/S1607-551X(09)70228-1

7. El-Nahas AR, Shokeir AA, El-Assmy AM, et al. Colonic perforation during percutaneous nephrolithotomy: study of risk factors. Urology 2006;67:937-941. https:// doi.org/10.1016/j.urology.2005.11.025 
8. Gökce Mi, Gülpınar Ö, Akpınar Ç, et al. Description of a novel method for renal puncture in supine percutaneous nephrolithotomy and comparison with a previously described method. Turk J Urol 2019;45:444448. https://doi.org/10.5152/tud.2019.33958

9. Ozdemir H, Erbin A, Sahan M, et al. Comparison of supine and prone miniaturized percutaneous nephrolithotomy in the treatment of lower pole, middle pole and renal pelvic stones: a matched pair analysis. Int Braz J Urol 2019;45:956-964. https://doi. org/10.1590/S1677-5538.IBJU.2019.0049

10. Patel RM, Okhunov Z, Clayman RV, Landman J. Prone versus supine percutaneous nephrolithotomy: What Is Your Position? Curr Urol Rep 2017;18:26. https://doi. org/10.1007/s11934-017-0676-9 